\title{
An implementation intervention to encourage healthy eating in centre-based child-care services: impact of the Good for Kids Good for Life programme
}

\author{
A Colin Bell ${ }^{1, *}$, Lynda Davies ${ }^{2}$, Meghan Finch ${ }^{2}$, Luke Wolfenden ${ }^{1,2}$, J Lynn Francis ${ }^{3}$, \\ Rachel Sutherland ${ }^{1,2}$ and John Wiggers ${ }^{1,2}$ \\ 'School of Medicine and Public Health, University of Newcastle, University Drive, Callaghan, NSW 2308, \\ Australia: ${ }^{2}$ Hunter New England Population Health, Wallsend, New South Wales, Australia: ${ }^{3}$ Research Centre \\ for Gender, Health and Aging (RCGHA), University of Newcastle, Newcastle, New South Wales, Australia
}

Submitted 10 October 2012: Final revision received 11 October 2013: Accepted 25 0ctober 2013: First published online 9 January 2014

\begin{abstract}
Objective: To determine the impact of an implementation intervention designed to introduce policies and practices supportive of healthy eating in centre-based child-care services. Intervention strategies included staff training, resources, incentives, follow-up support, and performance monitoring and feedback.

Design: A quasi-experimental design was used to assess change over 20 months in healthy eating policy and practice in intervention and comparison child-care services.

Setting: The Hunter New England (HNE) region of New South Wales (NSW), Australia.

Subjects: All centre-based child-care services ( $n$ 287) in the intervention region (HNE) were invited and 240 (91\% response rate) participated. Two hundred and ninety-six services in the rest of NSW were randomly selected as a comparison region and 191 participated (76\% response rate). A sub-analysis was conducted on those services that provided children food ( $n 196$ at baseline and $n 190$ at follow-up). Ninety-six provided menus for analysis at baseline (HNE, $n$ 36; NSW, $n$ 50) and 102 provided menus at follow-up (HNE, $n$ 50; NSW, $n$ 52).

Results: Services in the intervention region were significantly more likely to provide only plain milk and water for children $(P=0 \cdot 018)$ and to engage parents in nutrition policy or programmes $(P=0 \cdot 002)$. They were also more likely $(P=0 \cdot 056)$ to have nutrition policy on home packed food. In addition, menus of services that provided lunch were significantly more likely to comply with healthy eating guidelines for sweetened drinks $(P<0 \cdot 001)$, fruit $(P<0 \cdot 001)$ and vegetables $(P=0 \cdot 01)$.

Conclusions: An implementation intervention was able to modify policy and practice in a large number of child-care services so that they were more supportive of healthy eating.
\end{abstract}

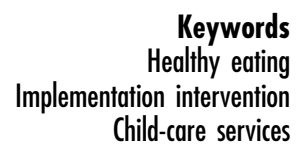

Keywords

ion intervention

Child-care services
Healthy eating patterns established early in life are likely to be sustained ${ }^{(1)}$, making the early years of childhood a critical window in which to establish these patterns. Consequently, centre-based child-care services, such as pre-schools and long-day-care centres (these centres provide care for $8 \mathrm{~h}$ or more per $\mathrm{d}$ for up to $5 \mathrm{~d}$ per week and usually enrol children aged from 6 weeks to 6 years), have been recognised as important settings for promoting healthy eating and physical activity and preventing excessive weight gain ${ }^{(2-5)}$. Initiatives promoting healthy eating in these settings can also reach large numbers of children. In Australia, for example, $50 \%$ of children aged up to 4 years use some form of centre-based child-care service (excluding pre-schools) ${ }^{(6)}$. Also, attendance at pre-school or a pre-school programme in long day care by children aged 3-6 years is $72 \%$, increasing to $82 \%$ in the year prior to commencing school ${ }^{(6)}$. Further, centrebased child-care services provide structured, modifiable environments and service staff recognise the promotion of healthy eating as a core responsibility ${ }^{(7)}$.

To encourage healthy eating, best practice guidelines for centre-based child-care services in Australia recommended, but did not require, that: (i) services have a nutrition policy; (ii) the policy covers the types of foods and beverages provided to children by the service or packed for children by parents; (iii) services provide plain 
milk or water only for children to drink during care; and (iv) services providing meals ensure that meals are consistent with dietary guidelines ${ }^{(8-14)}$. Further, research indicates that interventions in child care can help services improve their provision of and children's preferences for healthy food ${ }^{(15)}$. Despite this evidence and the availability of guidelines, services often fail to implement recommended policy and practices. For example, Jennings et al. found that possession of food and nutrition guidelines by full-day-care pre-schools did not consistently result in their use $\mathrm{e}^{(16)}$. Interventions to improve the implementation of nutrition policy and practice in centre-based child-care services therefore represent a considerable opportunity to improve child nutrition at a population level. However, few such implementation interventions have been conducted. A recently published systematic review of implementation interventions failed to find any controlled trials of interventions to improve the adoption of nutrition policies or practices in this setting ${ }^{(17)}$. A second review identified just four trials targeting policies and practices designed to influence the nutrition environment ${ }^{(15)}$. Two quasi-experimental trials testing interventions incorporating training and follow-up support for cooks to reduce total and saturated fat content of meals, nutrition education in the curriculum, parent meetings and take-home activities $^{(18)}$, and menu revision to include soya-enhanced foods ${ }^{(19)}$, reported positive outcomes. However, these trials involved fewer than seven child-care services. The third trial found that a staff wellness programme reduced staff consumption of sweet beverages and increased self-efficacy to work with parents on healthy eating and physical activity ${ }^{(20)}$. Also, staff were more likely to include fresh fruits and vegetables as part of children's regular meals. The fourth trial found no significant impact of the US Nutrition and Physical Activity Self-Assessment for Child Care (NAP SACC) intervention (a randomised controlled trial of eighty-four child-care services) based on an intention-to-treat analysis, although exploratory analysis found that centres completing most of the NAP SACC programme had an intervention effect on nutrition scores ${ }^{(21)}$. Additionally, the authors are aware of two further trials; the first examined the impact of the Munch and Move programme, a low-intensity intervention based on professional development for staff ${ }^{(22)}$. The trial found that children in centres where staff had been trained had significantly reduced servings of sweetened drinks in their lunchboxes by $0 \cdot 13$ servings. However, servings of fruits, vegetables and snacks (high in fat, sugar or salt) did not improve. The second, a community-wide, multi-strategy intervention focused on policy and practice change in centre-based child-care services in Victoria, successfully reduced childhood obesity and servings of energy-dense packaged snacks, fruit juice and cordial available while in care ${ }^{(23)}$.

The current evidence base provides little guidance to health practitioners and policy makers on how to scale up effective public health nutrition initiatives to a population level. The aim of the present study was to describe the impact of an implementation intervention designed to introduce policies and practices supportive of healthy eating in over two hundred centre-based child-care services in one region, namely the Hunter New England (HNE) region of New South Wales (NSW), Australia.

\section{Experimental methods}

\section{Design and setting}

We used a quasi-experimental design ${ }^{(24)}$ to evaluate the impact of a multi-component, implementation intervention to improve healthy eating (2007 to 2009) in a cohort of centre-based child-care services located in the intervention region. Results were compared with those collected from similar services from outside the region but within the same state (NSW). The intervention region is geographically large $\left(130000 \mathrm{~km}^{2}\right)$ with a demographically diverse population residing in metropolitan urban and suburban areas, regional centres, and rural and isolated remote communities. The region includes pockets of wealth and poverty, and an overall socioeconomic status lower than the NSW state average. The study was conducted according to the guidelines laid down in the Declaration of Helsinki and all procedures were approved by the Hunter New England Human Research Ethics Committee (HNEHREC 06/07/26/4.04). Written informed consent was obtained from authorised supervisors of participating services.

\section{Sample and recruitment}

In the state of NSW, long-day-care services provide centre-based care for $8 \mathrm{~h}$ or more per $\mathrm{d}$ for $5 \mathrm{~d}$ per week and usually enrol children aged from 6 weeks up to 6 years. Pre-schools provide centre-based care for $6-8 \mathrm{~h}$ per $\mathrm{d}$ and enrol children aged between 3 and 6 years. Both long-day-care services and pre-schools (collectively, 'centre-based child-care services') provide educational activities for children aged 3 to 5 years to assist in their preparation for school. In most pre-schools and long day care, parents are responsible for providing children's food. However, some services $30 \%$ in the intervention region) have cooks on site and provide snacks and lunch.

Details of all licensed long-day-care and pre-school services for NSW were obtained from the State Office of Childcare from Family and Community Services (the licensing agency). All services ( $n$ 287) located within the intervention region were invited to participate, excluding services catering for children with special needs such as intellectual or physical disabilities. A simple $10 \%$ random sample of eligible centre-based child-care services in all other regions of the state of NSW was invited to participate in the study as the comparison group ( $n$ 296). Authorised supervisors of eligible services were sent a letter inviting them to participate. Approximately two weeks after receipt 
of the letter, a trained research assistant telephoned services to assess their interest in participation and confirm eligibility. In total, 240 (91\% response rate) services in the intervention region participated along with 191 (76\% response rate) in the comparison region.

\section{Healtby eating policies and practices}

The policies and practices targeted for adoption by services were based on existing recommended best practice nutrition guidelines for the sector ${ }^{(25)}$ and reviewed by an expert advisory group with representation from Family and Community Services, the NSW Department of Health, authorised supervisors (managers) from local services, health promotion practitioners, dietitians and paediatric researchers. The targeted policies and practices were:

1. Staff training in nutrition.

2. Policy guiding the content of food and drinks provided to children by the service.

3. Policy guiding the content of food and drinks packed for children by parents.

4. Provision of non-sweetened drinks (milk and water) only to children during care.
5. Parent participation in nutrition policy or programmes.

6. Provision of foods to children consistent with dietary guidelines (for services that provide meals to children) and accreditation requirements ${ }^{(8,14)}$.

\section{Implementation intervention}

The implementation intervention was part of a large childhood obesity prevention initiative (www.goodforkids. nsw.gov.au) from 2006 to 2011 in HNE, NSW and was conducted by Hunter New England Population Health. In child-care services, it was based on practice change and capacity building theoretical frameworks ${ }^{(26-29)}$, and consisted of the following evidence-based strategies ${ }^{(30,31)}$, to support adoption of policy and practice changes by services: (i) identifying leaders and obtaining their support and endorsement of the programme and targeted policy and practices; (ii) the provision of professional development for staff; (iii) the use of small incentives; (iv) resource provision; (v) performance monitoring and feedback; and (vi) follow-up support (see Table 1 for a detailed description of intervention strategies) ${ }^{(32)}$.

Table 1 Domain and key strategies of the implementation intervention for children's services in Hunter New England region, New South Wales, Australia (2006-2009)

\begin{tabular}{ll}
\hline Domain & Healthy eating implementation strategies \\
\hline $\begin{array}{l}\text { Identifying leaders and obtaining } \\
\text { support (2007-2009) }\end{array}$ & $\begin{array}{c}\text { Endorsement of the intervention by the Department of Community Services, local authorised } \\
\text { supervisors and dietitians was communicated to services through print materials } \\
\text { Authorised supervisors from all services were encouraged to demonstrate support for the } \\
\text { intervention at staff meetings and through the implementation or amending of an organisational } \\
\text { nutrition policy } \\
\text { Staff training was conducted by HNEPH dietitians and children's services advisors from the NSW } \\
\text { Department of Community Services }\end{array}$
\end{tabular}

Training and professional development (2007)

Information, tools and resources (2008-2009)

Follow-up support (2007-2009)

Performance monitoring and feedback (2007-2009)
One staff member from each service was invited to a $6 \mathrm{~h}$ nutrition workshop

CD-ROM and paper-based modules of training were made available for all staff of all services

For services providing meals to children in care, a cook and an authorised supervisor (service manager) from each service were invited to participate in a $6 \mathrm{~h}$ healthy menu planning workshop

All services received a nutrition resource kit including the Good for Kids, Good for Life Best Practice Nutrition Guidelines for Children's Services, as well as resources such as a policy template, nutrition games, activities and learning experiences, healthy lunchbox guides to assist parents to pack healthy foods and drinks, and a resource manual for cooks including nutrition guidelines, menu review tools and healthy recipes

All services were offered a 20 min telephone support call to reinforce key programme messages, identify barriers to practice change and provide additional advice and support

All services received five support newsletters to reinforce key messages and highlight case studies of successful services

All services were provided with a free contact number direct to a member of the project team for any further queries or support

For services providing food to children and supplying a menu for audit during baseline data collection, during the telephone support call, authorised supervisors were provided feedback regarding how their menu could be improved. Services were also invited to submit a future menu for review and written feedback

Information collected as part of the (i) baseline data collection (including the baseline evaluation menu audit), (ii) pen-and-paper survey of intervention services at the nutrition workshops, (iii) telephone support call with the service and (iv) intervention services only menu audit was used to monitor adoption of intervention components and provide performance feedback regarding individual service implementation during the telephone call and as a written feedback report. Stage of change theory ${ }^{(14)}$ was incorporated into both forms of performance feedback 
In addition, services providing meals to children (at least lunch and one snack) were offered feedback on how consistent their menus were with dietary guidelines. The child-care intervention was delivered from June 2007 to March 2009 by Hunter New England Population Health staff who worked with regional representatives of the Department of Community Services and service staff to implement the strategies mentioned above. An in-principle agreement was drawn up to ensure ongoing commitment to common goals and to establish clear roles and responsibilities between agencies.

\section{Comparison services}

There were no state-wide initiatives in NSW centre-based child-care services promoting healthy eating at the beginning of the intervention period (2007). However, from July 2008 onwards, pre-school services (not including long day care) in NSW were able to access implementation support via a government-supported programme that aimed to promote physical activity and healthy eating for children ${ }^{(22)}$.

\section{Data collection}

\section{Healthy eating policies and practices}

Data on healthy eating policies and practices were collected by computer-assisted telephone interview (CATI) with consenting authorised supervisors. Baseline data were collected between December 2006 and May 2007 and follow-up occurred 22 months after initiation of the intervention between March and August 2009.

\section{Menus}

A sub-analysis was conducted on those services that provided children food ( $n 196$ at baseline and $n 190$ at follow-up). Ninety-six provided menus for analysis at baseline (HNE, $n$ 36; NSW, $n$ 50) and 102 provided menus at follow-up (HNE, $n$ 50; NSW, $n$ 52).

All services were invited during the CATI to submit a copy of their current two-week menu. Services were reminded twice by fax, email or telephone (at baseline only). At baseline they were also asked to record details of specific menu items such as the types of processed foods (e.g. breakfast cereals), milk, fruit and vegetables listed and the foods included in mixed dishes. Services not providing sufficient information for menu analysis at baseline were re-contacted once by telephone and additional information was requested.

\section{Measures}

\section{Service characteristics}

The CATI included items assessing service type (long day care or pre-school), service size (average number of children enrolled and attending per day, number of staff and number of Indigenous children enrolled), postcode and operational characteristics (average opening hours per day, number of days per week open).

\section{Healthy eating policies and practices}

The CATI also assessed whether services had: (i) staff who had participated in professional development or specific training on healthy eating or nutrition for children (yes-all, yes-some, none have, don't know); and (ii) a written policy or policies that supported providing meals that meet children's nutritional needs, packing of healthy lunchboxes and provision of water or plain milk for children to drink.

\section{Nutritional quality of lunch menus}

Guidelines recommend that centre-based child-care service menus do not include items high in fat, salt and/or sugar or sweetened drinks. They also recommend that water is available at every eating occasion, that one serving of fruit is listed on the menu each day and that the number of servings of vegetables is appropriate to the hours the service is open. From the menus provided, a dietitian (L.D.) extracted the following information for the first four eating occasions of each day of the two-week menu (10 d):

1. Number of times processed foods high in fat, salt and/or sugar (fat: $>20 \mathrm{~g}$ of fat/100 g or $>5 \mathrm{~g}$ saturated fat/100 g; salt: $>600 \mathrm{mg}$ of salt/100 g; sugar: $>15 \mathrm{~g}$ of sugar $/ 100 \mathrm{~g})^{(12)}$, excluding core dairy products (cheese, milk, yoghurt, plain custard), dried fruit, ham, margarine/oils and spreads (e.g. vegemite, jam, peanut butter), were listed on the menu each day. When the brand name was known, nutrition information was sourced from the packaging, the manufacturer's website or an independent food and nutrition information website for known products (www.calorieking.com.au). When the brand name was unknown, nutrition information for the 'average all brands' option on the Calorie King website was used for that type of processed food.

2. Number of times sweetened drinks (defined as: juice, fruit drink, cordial, flavoured milk, soft drink) were listed on the menu each day.

3. Number of times water was listed on the menu each day.

4. Number of 'child size' servings of fruit (fresh, dried or canned) listed on the menu each day (a piece of fruit, fruit platter, mixed fruit and dried fruit were counted as 1 serving; fruit contained in cereals and fruit juice were not counted).

5. Number of 'child size' servings of vegetables listed on the menu each day (vegetable-based main meal and mixed vegetables were counted as 2 servings; a side salad and a dish which includes vegetables, such as chicken and vegetable pie, were counted as 1 serving; and salad in a sandwich was counted as 0.5 serving).

A 'child size' serving is half a standard serving as described in the Australian Guide to Healthy Eating ${ }^{(10)}$. 
Consistent with the guidelines mentioned earlier, menus were then classified into the following categories:

1. No high-fat, -salt and/or -sugar processed food menu items.

2. No sweetened drink menu items.

3. Water with every eating occasion.

4. One child-size serving of fruit listed on the menu each day.

5. The number of child-size servings of vegetables listed on the menu each day is appropriate to hours open (i.e. at least one if open $<8 \mathrm{~h}$; at least two if open $8 \mathrm{~h}$; or at least three if open $>8 \mathrm{~h}$ ).

\section{Data analysis}

Analyses were performed using the statistical software package SAS version 9.2. All statistical tests were twotailed with an $\alpha$ of $0 \cdot 05$. Descriptive statistics were used to describe the study sample. Sample characteristics were compared using Fisher's exact test (percentages), the $t$ test (means) and Wilcoxon's two-sample test (medians). The $\chi^{2}$ test for categorical variables and the paired $t$ test for continuous variables were used to compare changes in organisational policies and practices reported pre- and post-intervention in HNE and over the same period in the comparison area. Logistic regression, within a generalised estimating equation framework, was used to compare rates of change in policies and practices at baseline and follow-up between intervention and comparison areas. The logistic regression model included terms for time, region and the interaction of time and region. The $P$ value from the interaction term was used to determine if there was a statistically significant difference in change between regions. Characteristics of services were not adjusted for in the logistic regression model as we were looking at change within services and the baseline score of the services effectively controlled for potential differences in baseline characteristics between the two regions.

For menu analyses, linear and logistic models were fitted to compare changes in compliance with menu recommendations over the intervention period between intervention and comparison regions. When the baseline for both regions was essentially zero, the post values were compared using frequency tables and Fisher exact tests.

\section{Results}

\section{Response rates and sample characteristics}

Of the 287 services in the intervention region invited to participate in the study, six were ineligible, five were unable to be contacted and fifteen did not wish to participate, leaving 261 (91\% response rate). Of the 296 randomly selected services from NSW, five were ineligible, sixteen could not be contacted and 251 agreed to participate ( $85 \%$ response rate). At follow-up, 240 services from the intervention region (91\% of those surveyed at baseline) and 191 from NSW (76\% of those surveyed at baseline) completed the survey and were therefore included in the analyses. Of the services included in the analysis, services in the intervention region were significantly more likely to be located in areas of lower socio-economic advantage and in rural locations than those in NSW (Table 2). Intervention services were also significantly more likely to have Indigenous children enrolled. There were no significant differences in the socio-economic or geographic characteristics of intervention or comparison services that did and did not participate in the post-intervention CATI $(P=0 \cdot 07-0 \cdot 94$; data not shown).

Table 2 Baseline sociodemographic, geographic and service characteristics by region of children's services participating in baseline and follow-up surveys

\begin{tabular}{|c|c|c|c|c|c|c|}
\hline \multirow[b]{2}{*}{ Characteristic } & \multirow[b]{2}{*}{ Category } & \multicolumn{2}{|c|}{$\mathrm{HNE}^{*}(n$ 240) } & \multicolumn{2}{|c|}{$\mathrm{NSW+}(n$ 191) } & \multirow[b]{2}{*}{$P$ value } \\
\hline & & $\begin{array}{l}\text { Mean or } \\
\text { Median }\end{array}$ & $\begin{array}{l}95 \% \mathrm{Cl} \text { or } \\
\text { Min, max }\end{array}$ & $\begin{array}{l}\text { Mean or } \\
\text { Median }\end{array}$ & $\begin{array}{l}95 \% \mathrm{Cl} \text { or } \\
\text { Min, max }\end{array}$ & \\
\hline Ranked in top $50 \%$ of NSW SEIFA $(\%)$ & & \multicolumn{2}{|c|}{41} & \multicolumn{2}{|c|}{69} & $<0.0001$ \\
\hline \multirow[t]{4}{*}{ Geographic locality (\%) } & Major city & \multicolumn{2}{|c|}{39} & \multicolumn{2}{|c|}{69} & $<0.0001$ \\
\hline & Inner regional & \multicolumn{2}{|c|}{28} & \multicolumn{2}{|c|}{19} & \\
\hline & Outer regional & \multicolumn{2}{|c|}{30} & \multirow{2}{*}{\multicolumn{2}{|c|}{$\begin{array}{l}8 \\
2\end{array}$}} & \\
\hline & Remote/very remote & \multirow{2}{*}{\multicolumn{2}{|c|}{$\begin{array}{r}4 \\
65\end{array}$}} & & & \\
\hline Services with Indigenous children (\%) & & & & \multicolumn{2}{|c|}{$\begin{array}{r}2 \\
39\end{array}$} & $<0.0001$ \\
\hline \multirow{2}{*}{\multicolumn{2}{|c|}{$\begin{array}{l}\text { Number of children enrolled } \\
\text { Hours open }\end{array}$}} & $79 \cdot 3$ & $74 \cdot 6,84 \cdot 0$ & $73 \cdot 9$ & $68 \cdot 4,79 \cdot 4$ & \\
\hline & & $8 \cdot 7$ & $8 \cdot 5,8.9$ & $9 \cdot 3$ & $9 \cdot 0,9 \cdot 5$ & \\
\hline Days open & & $4 \cdot 8$ & $4 \cdot 7,4 \cdot 9$ & 4.9 & $4 \cdot 8,5 \cdot 0$ & \\
\hline Tertiary-educated staff§ & & $1 \cdot 0$ & $0 \cdot 0,7 \cdot 0$ & $1 \cdot 0$ & $0 \cdot 0,7 \cdot 0$ & \\
\hline Contact staff per day§ & & $5 \cdot 0$ & $2 \cdot 0,20 \cdot 0$ & $5 \cdot 0$ & $2 \cdot 0,25 \cdot 0$ & \\
\hline
\end{tabular}

HNE, Hunter New England (intervention region); NSW, New South Wales (comparison region); SEIFA, Socio-Economic Index for Areas.

*Missing, $n 19$.

+Missing, $n 25$.

$\ddagger$ This index ranks geographic areas across Australia in terms of their socio-economic characteristics using information such as low income and low education as markers of relative socio-economic disadvantage.

$\S$ Values are median and min, max. 


\section{Services that provided food}

At baseline, 36/71 (51\%) intervention services and 50/125 (40\%) comparison services provided a menu for analysis. At follow-up, 50/82 (61\%) intervention services and 52/106 (49\%) comparison services provided a menu (Table 3). At baseline, intervention services were open slightly longer hours, had a higher number of children and contact staff, a higher proportion of tertiary-educated staff and a greater proportion were located in areas of lower socio-economic advantage. Similarly, at follow-up intervention services had larger numbers of children and contact staff and a higher number of tertiary-educated staff. However, differences in socio-economic advantage were not evident.

\section{Healtby eating policy and practice}

Changes in healthy eating policy and practice over time are shown in Table 4. Within the intervention region, significant improvements were observed in the proportion of staff with nutrition training ( 27 percentage points), the proportion of services with policy guiding the nutrition content of food and drink packed by parents (6 percentage points), the proportion of services providing only water or plain milk (27 percentage points) and parent participation in nutrition policy or programmes (12 percentage points). Within the comparison region, the proportion of staff with nutrition training (21 percentage points) and the proportion of services providing only water or plain milk to children (24 percentage points) also increased significantly. When these changes in the intervention and comparison regions were compared, changes in the intervention region were significantly greater than those observed in the comparison region with the exception of staff training and services having policy on packed lunches (although this came close to statistical significance, $P=0 \cdot 056$ ). Counter to an intervention effect, the proportion of services with policy guiding the nutrition content of food provided to children by the service decreased significantly in both the intervention and comparison regions.

\section{Menus in services providing lunch meals}

A significant reduction was observed in the average number of high-fat, -salt and/or -sugar items on menus in intervention services (Table 5). Significant reductions were also observed in the number of sweetened drink items and servings of fruit. There was also a significant increase in servings of vegetables. In the comparison region, a significant increase in servings of vegetables was observed. Changes in the average number of items on menus were significantly different between the intervention and comparison region for all the items assessed.

Table 6 shows changes in the compliance of menus with healthy eating guidelines. In the intervention region, there was no significant increase in the proportion of services complying with guidelines on processed foods

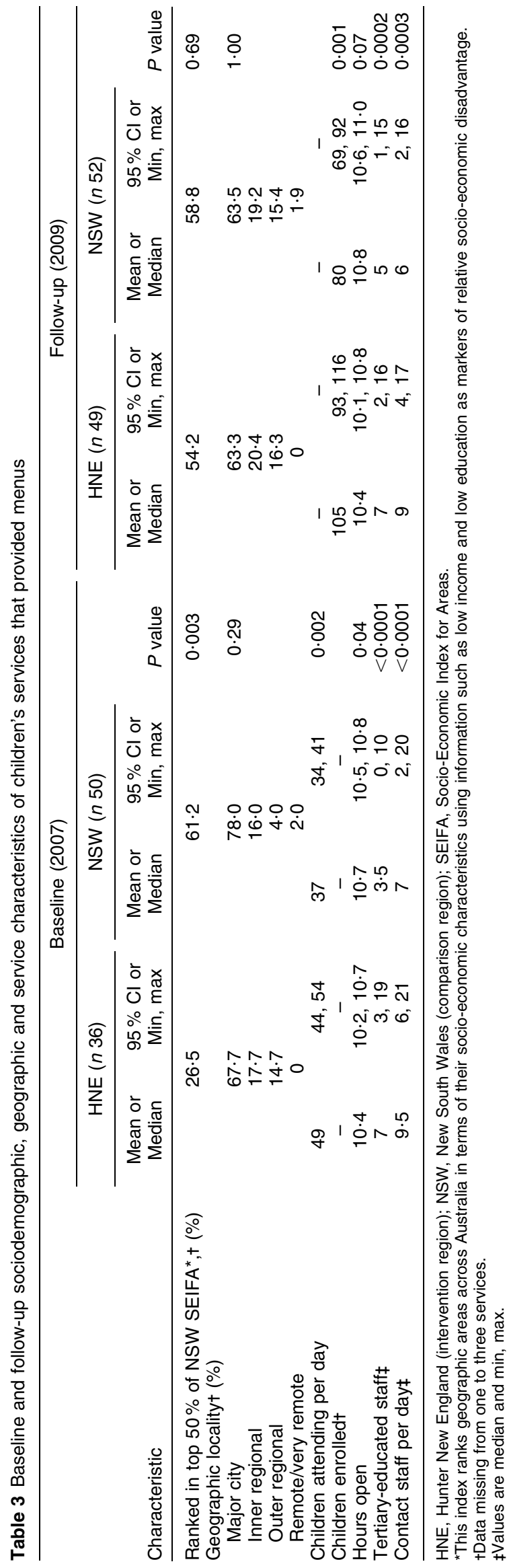


Table 4 Changes in healthy eating policy and practice of child-care services over time (2006-2009)

\begin{tabular}{|c|c|c|c|c|c|c|c|}
\hline \multirow[b]{2}{*}{ Policy or practice } & \multicolumn{2}{|c|}{ HNE ( $n$ 240) } & \multirow[b]{2}{*}{$P$ value } & \multicolumn{2}{|c|}{ NSW ( $n$ 191) } & \multirow[b]{2}{*}{$P$ value } & \multirow{2}{*}{$\frac{\text { Interaction term }}{P \text { value }}$} \\
\hline & $\begin{array}{l}\text { Baseline } \\
\quad(\%)\end{array}$ & $\begin{array}{l}\text { Follow-up } \\
\text { (\%) }\end{array}$ & & $\begin{array}{l}\text { Baseline } \\
\quad(\%)\end{array}$ & $\begin{array}{l}\text { Follow-up } \\
\text { (\%) }\end{array}$ & & \\
\hline Staff with nutrition training & 53 & 80 & $<0.0001$ & 51 & 72 & $<0.0001$ & $0 \cdot 184$ \\
\hline $\begin{array}{l}\text { Services with a policy guiding the content } \\
\text { of food and drinks provided to children } \\
\text { by the service* }\end{array}$ & 88 & 65 & $<0.001$ & 85 & 79 & $0 \cdot 194$ & 0.06 \\
\hline $\begin{array}{l}\text { Services with a policy guiding the content } \\
\text { of food and drinks packed for children } \\
\text { by parentst }\end{array}$ & 91 & 97 & 0.029 & 89 & 86 & 0.637 & 0.056 \\
\hline $\begin{array}{l}\text { Services providing only water or plain } \\
\text { milk to children }\end{array}$ & 68 & 95 & $<0.0001$ & 58 & 82 & $<0.0001$ & 0.018 \\
\hline $\begin{array}{l}\text { Parent participation in nutrition policy or } \\
\text { programmes }\end{array}$ & 65 & 77 & 0.003 & 65 & 59 & $0 \cdot 1742$ & 0.002 \\
\hline
\end{tabular}

HNE, Hunter New England (intervention region); NSW, New South Wales (comparison region).

${ }^{*}$ For services providing any meals or snacks to children at baseline ( $n 91$ for HNE and 112 for NSW).

tFor services where parents provide all meals and snacks for children at baseline ( $n 149$ for HNE and 79 for NSW).

Table 5 Change over time (2006-2009) in the mean number of items or servings of key foods and drinks each day listed on menus of services providing food, by region

\begin{tabular}{|c|c|c|c|c|c|c|c|}
\hline \multirow[b]{2}{*}{ Food or drink item } & \multicolumn{2}{|c|}{ HNE } & \multirow[b]{2}{*}{$P$ value } & \multicolumn{2}{|c|}{ NSW } & \multirow[b]{2}{*}{$P$ value } & \multirow{2}{*}{$\begin{array}{c}\text { Interaction term } \\
P \text { value }\end{array}$} \\
\hline & $\begin{array}{l}\text { Baseline } \\
(n 36)\end{array}$ & $\begin{array}{l}\text { Follow-up } \\
\quad(n 50)\end{array}$ & & $\begin{array}{l}\text { Baseline } \\
(n 50)\end{array}$ & $\begin{array}{l}\text { Follow-up } \\
\qquad(n 52)\end{array}$ & & \\
\hline $\begin{array}{l}\text { High-fat, -salt and/or -sugar } \\
\text { processed food menu items }\end{array}$ & $1 \cdot 6$ & $0 \cdot 7$ & $<0.01$ & $1 \cdot 4$ & $1 \cdot 2$ & 0.09 & 0.001 \\
\hline Sweetened drink menu items & $0 \cdot 4$ & $0 \cdot 0$ & 0.002 & 0.5 & $0 \cdot 4$ & $0 \cdot 29$ & $<0.001$ \\
\hline Child-sized servings of fruit & $1 \cdot 9$ & $1 \cdot 4$ & 0.002 & $2 \cdot 0$ & $1 \cdot 9$ & $0 \cdot 79$ & 0.05 \\
\hline Child-sized servings of vegetables & $1 \cdot 4$ & $2 \cdot 4$ & $<0.001$ & $1 \cdot 5$ & $1 \cdot 7$ & 0.04 & $<0 \cdot 001$ \\
\hline
\end{tabular}

HNE, Hunter New England (intervention region); NSW, New South Wales (comparison region).

Table 6 Change in the proportion of children's services providing food (2006-2009) whose menus met healthy eating guidelines

\begin{tabular}{|c|c|c|c|c|c|c|c|}
\hline \multirow[b]{2}{*}{ Guideline } & \multicolumn{2}{|c|}{ HNE } & \multirow[b]{2}{*}{$P$ value } & \multicolumn{2}{|c|}{ NSW } & \multirow[b]{2}{*}{$P$ value } & \multirow{2}{*}{$\begin{array}{c}\text { Interaction term } \\
P \text { value }\end{array}$} \\
\hline & $\begin{array}{l}\text { Baseline } \\
(n 36)(\%)\end{array}$ & $\begin{array}{l}\text { Follow-up } \\
(n \text { 50) (\%) }\end{array}$ & & $\begin{array}{l}\text { Baseline } \\
(n 50)(\%)\end{array}$ & $\begin{array}{l}\text { Follow-up } \\
(n \text { 52) (\%) }\end{array}$ & & \\
\hline $\begin{array}{l}\text { No high-fat, -salt and/or -sugar } \\
\text { processed food menu items }\end{array}$ & 0 & 10 & 0.07 & 2 & 2 & $1 \cdot 00$ & $0 \cdot 11$ \\
\hline No sweetened drink menu items & 50 & 96 & $<0.01$ & 42 & 52 & $0 \cdot 33$ & $<0.001$ \\
\hline Water with every eating occasion & 11 & 20 & 0.38 & 16 & 23 & $0 \cdot 62$ & $1 \cdot 00$ \\
\hline $\begin{array}{l}\text { One child-sized serving of fruit listed on } \\
\text { the menu each day }\end{array}$ & 0 & 34 & $<0.01$ & 2 & 6 & $0 \cdot 62$ & $<0.001$ \\
\hline $\begin{array}{l}\text { Number of child-sized servings of } \\
\text { vegetables listed on the menu each } \\
\text { day is appropriate to hours open }\end{array}$ & 0 & 20 & $<0 \cdot 01$ & 0 & 4 & $1 \cdot 00$ & 0.01 \\
\hline
\end{tabular}

HNE, Hunter New England (intervention region); NSW, New South Wales (comparison region).

high in fat, salt or sugar in spite of a significant reduction in the average number of items (Table 5). However, significant improvements were observed in the proportion of services that excluded sweetened drinks from the menu, included only one child-sized serving of fruit each day and included an appropriate number of child-sized servings of vegetables. A 10 percentage point increase in the proportion of menus with no high-fat, -salt and/or -sugar food items was not significant $(P=0.07)$ and no statistically significant change was observed in the number of menus that indicated water was provided on every eating occasion. In the comparison region, small improvements were observed but there were no significant changes. When intervention and comparison regions were compared, significantly greater improvements were observed in the intervention region for menus meeting guidelines for sweetened drinks, fruit and vegetables (Table 6).

\section{Discussion}

As the largest trial to date of an implementation intervention to improve nutritional practices of centre-based child-care 
services, the present study provides a unique contribution to the evidence base regarding approaches to achieving population-wide improvements in nutrition policy and practice. Overall, the findings are consistent with the limited evidence to date of successful implementation interventions which have shown improvements in food service practices, particularly in relation to sweetened drinks and fruit and vegetables ${ }^{(15,22,23)}$. The findings also add to the literature by demonstrating changes of a larger magnitude and/or demonstrating change in a larger number of services than has previously been observed.

Changes in policy have been observed in Australian centre-based child-care services as part of South Australian (forty-four centres) and Western Australian (seventy-six centres) evaluations of an intervention to improve nutrition in long-day-care centres called Start Right Eat Right ${ }^{(33,34)}$. In South Australia, policy change was assessed against eighteen criteria and services met an average of 8.4 criteria pre-intervention and $17 \cdot 1$ criteria post-intervention ${ }^{(34)}$. However, policy was assessed only in ten centres. In the Western Australia study, menu changes were also observed. Feedback from seventy-two of the seventy-six centres registered in the scheme at 9 months showed that sixty-six (92\%) had made changes (unspecified) to their menus ${ }^{(33)}$. One factor limiting the impact of our implementation intervention on policy may have been the high proportion of services that had policy in place at baseline ( $\geq 88 \%$ ), leaving little room for improvement. There were also indications of barriers to policy implementation. For example, while most services had policy in place at baseline, many also had menus that did not comply with the policy (see Table 6). Also, the proportion of services reporting that they had policy guiding the content of food and drinks provided to children by the service decreased, rather than increased, over time and to a greater extent in intervention $(-23$ percentage points) than comparison $(-6$ percentage points) services $(P=0 \cdot 06)$. The lack of a single, user-friendly policy guideline for use in centre-based child-care services may explain why some services have difficultly implementing policy. The absence of uniform standards on healthy eating has also been a problem for child-care settings in the USA ${ }^{(5)}$. We recommend a simple, single set of guidelines be developed and endorsed to guide menu planning in NSW centre-based child-care services and that parents participate in development.

The level of training achieved in the present study (80\%) was similar to that for Start Right Eat Right in South Australia, where $88 \%$ of eligible centre staff were trained $^{(34)}$. A likely explanation for the lack of a significant difference in training between the intervention and comparison region in our study was that training was offered in the comparison region during the intervention. From July 2008, all comparison (but not intervention) pre-schools had access to Munch and Move - a playbased approach to supporting healthy eating and physical activity habits in young children. Munch and Move was less intensive than Good for Kids. Pre-schools were provided with a one-day professional development workshop, resources (manuals, fact sheets, games, small grants) and local health district support visits. It was also less extensive. Over the intervention period, fifty-two training workshops were held in forty locations across NSW (excluding the intervention region). However, only $18 \%(35 / 191)$ of service managers from our comparison group reported that staff attended the Munch and Move training.

Our finding that the proportion of services in the intervention region whose menus met guidelines for fruit, vegetables and sweetened drinks increased significantly supports provision of specific training for cooks. The findings regarding sweetened drinks were particularly encouraging given that $50 \%$ of services had these drinks on menus at baseline and previous studies which show persistent availability of sweetened drinks such as flavoured milk in child-care centres ${ }^{(35)}$. For example, in the US-based early childhood education programme Head Start, $55 \%$ of schools, where the school or school district provided meals, served flavoured milk $^{(36)}$. We have shown that, with appropriate policy and associated support, centre-based child-care services can almost completely remove sweetened drinks from their menus and we recommend this as a focus of future implementation interventions.

The intervention had little impact on processed food menu items high in fat, salt or sugar. This is consistent with the findings of the Munch and Move programme that had no impact on items high in fat, sugar or salt in lunchboxes ${ }^{(22)}$. In our study, this may have been because those preparing menus were unclear about what the guidelines were with respect to these foods. A simpler menu planning guide for centre-based child-care services, similar to that used by schools in $\mathrm{NSW}^{(37)}$, may help overcome this challenge.

Strengths of the study include the large number of services that participated, the high response rates and the length of the intervention. These strengthen the robustness of the findings and their generalisability to NSW centre-based child-care services. Limitations include the challenges associated with using a real-world comparison that may have diluted the impact of the intervention and the inability of the study to determine the impact of the intervention on the eating behaviour of children. Also, our evaluation of changes in centre-based child-care services relied on self-report, potentially biasing reporting of practices in the direction of a positive intervention effect. While effort was made to collect specific nutrient information from menus and chefs, and qualified dietitians converted this information into the food categories of interest, this proxy method is not as accurate as assessing children's actual food and beverage intake. Finally, the evaluation survey was not all encompassing. 
In the interests of time, only a limited number of questions could be asked as part of the telephone interview and therefore we may have missed positive changes simply because they were not measured.

This implementation intervention increased the number of centre-based child-care services that: (i) had policy guiding foods and drinks packed for children by parents; (ii) served only plain milk and water for children to drink; and (iii) engaged parents in nutrition policy and programmes. It also improved compliance of menus with healthy eating guidelines in services providing lunch. Because we worked with existing centre-based child-care services staff and infrastructure, our capacitybuilding approach may be a more cost-effective method of creating healthy environments for young children in Australia than programmes requiring delivery by specialist staff ${ }^{(38)}$.

\section{Acknowledgements}

Sources of funding: This research was funded by NSW Ministry of Health. The Ministry of Health had no role in the design, analysis or writing of this article. Conflicts of interest: The authors declare that they have no conflicts of interest. Ethics: The study was approved by the Hunter New England Human Research Ethics Committee (HNEHREC 06/07/26/4.04). Authors' contributions: Authors A.C.B., L.D., M.F. and L.W. contributed equally to this work. A.C.B. was involved in the study design, interpretation of the findings and drafted the manuscript. L.D., M.F. and L.W. participated in the data collection and interpretation. J.L.F. carried out the statistical analyses. J.W. was involved in designing the study and revising the manuscript. All authors read and approved the final manuscript. Acknowledgements: The authors acknowledge the authorised supervisors and centre directors who provided information on their services for this study and the staff and children of Hunter New England Children's Services who participated in the Good for Kids, Good for Life programme.

\section{References}

1. Birch L (1999) Development of food preferences. Annu Rev Nutr 19, 41-62.

2. Birch L \& Ventura A (2009) Preventing childhood obesity: what works? Int J Obes (Lond) 33, Suppl. 1, S74-S81.

3. Bluford DA, Sherry B \& Scanlon K (2007) Interventions to prevent or treat obesity in preschool children: a review of evaluated programs. Obesity (Silver Spring) 15, 1356-1372.

4. Story M, Kaphingst KM, Robinson-O'Brien R et al. (2008) Creating healthy food and eating environments: policy and environmental approaches. Annu Rev Public Health 29, 253-272.

5. Story M, Kaphingst KM \& French S (2006) The role of child care settings in obesity prevention. Future Child 16, 143-168.

6. Australian Bureau of Statistics (2009) Childhood Education and Care, June 2008 (Reissue). Catalogue no. 4402.0. Canberra: ABS.
7. Pagnini D, Wilkenfeld R, King L et al. (2007) Early childhood sector staff perceptions about overweight and obesity: the Weight of Opinion Study. Health Promot J Aust 18, 149-154.

8. National Health and Medical Research Council (2003) Dietary Guidelines for Children and Adolescents in Australia incorporating the Infant Feeding Guidelines for Health Workers. Canberra: Commonwealth of Australia.

9. National Health and Medical Research Council (2006) Nutrient Reference Values for Australia and New Zealand. Canberra: Commonwealth of Australia.

10. Children's Health Development Foundation (1998) The Australian Guide to Healthy Eating - Nutrition Educator's Material. Canberra: Commonwealth of Australia.

11. The Children's Hospital at Westmead (2004) Healthy Eating for Toddlers Factsheet. http://www.chw.edu.au/parents/ (accessed June 2008).

12. CHOICE magazine (2011) Food for Kids criteria. http://www. choice.com.au/reviews-and-tests/babies-and-kids/food-forkids/kids-food/food-for-kids.aspx (accessed December 2013).

13. New South Wales Government (2013) Children's Services Regulation 2004 [2004-260]. Current version for 1 January 2011 to date. http://www.legislation.nsw.gov.au/fullhtml/ inforce/subordleg $+260+2004+$ FIRST $+0+\mathrm{N}$ (accessed December 2013).

14. National Childcare Accreditation Council (2005) Quality Improvement and Accreditation System. Quality Practices Guide, 1st ed. Canberra: Australian Government.

15. Larson N, Ward DS, Neelon SB et al. (2011) What role can child-care settings play in obesity prevention? A review of evidence and call for research efforts. J Am Diet Assoc 111, 1343-1362.

16. Jennings A, McEvoy S \& Corish C (2011) Nutrition practices in full-day-care pre-schools. J Hum Nutr Diet 24, 245-259.

17. Rabin BA, Glasgow R, Kemer JF et al. (2010) Dissemination and implementation research on community-based cancer prevention. Am J Prev Med 38, 443-456.

18. Williams C, Strobino B, Bollella M et al. (2004) Cardiovascular risk reduction in preschool children: the "Healthy Start' Project. J Am Coll Nutr 23, 117-123.

19. Endres J, Barter S, Theodora P et al. (2003) Soy-enhanced lunch acceptance by preschoolers. J Am Diet Assoc 103, 346-351.

20. Gosliner W, James P, Yancey A et al. (2010) Impact of a worksite wellness program on the nutrition and physical activity environment of child care centers. Am J Health Promot 24, 186-189.

21. Ward D, Benjamin S, Ammerman A et al. (2008) Nutrition and physical activity in child care: results from an environmental intervention. Am J Prev Med 35, 352-356.

22. Hardy LL, King L, Kelly B et al. (2010) Munch and Move: evaluation of a preschool healthy eating and movement skill program. Int J Behav Nutr Phys Act 7, 80.

23. De Silva Sanigorski A, Bell AC, Kremer PK et al. (2010) Reducing obesity in early childhood: results from Romp and Chomp, an Australian community-wide intervention program. Am J Clin Nutr 91, 831-840.

24. Murray DM, Varnell SP \& Blitstein JL (2004) Design and analysis of group randomized trials: a review of recent methodological developments. Am J Public Health 94, 423-432.

25. NSW Health (2005) Caring for Children: Food, Nutrition and Fun Activities: A Practical Guide to Meeting the Food and Nutrition Needs of Children in Care, 4th ed. Sydney: NSW Department of Health.

26. Gill T, King L \& Webb K (2005) Best Options for Promoting Healthy Weight and Preventing Weight Gain in NSW. Sydney: NSW Centre for Public Health Nutrition and NSW Department of Health.

27. Rogers EM (2003) Diffusion of Innovations, 5th ed. New York: Free Press. 
28. Simmons A, Borys JM \& Swinburn BA (2010) Community interventions - planning for sustainability. In Preventing Childhood Obesity: Evidence, Policy and Practice, pp. 220-231 [E Waters, B Swinburn, R Uauy et al., editors]. Oxford: Wiley-Blackwell.

29. Smith B, Tang K \& Nutbeam D (2006) WHO health promotion glossary: new terms. Health Promot Int $\mathbf{2 1}$, 340-345.

30. De Groot F, Robertson NM, Swinburn BA et al. (2010) Increasing community capacity to prevent childhood obesity: challenges, lessons learned and results from the Romp \& Chomp intervention. BMC Public Health 10, 522.

31. NSW Health Department (2001) A Framework for Building Capacity to Improve Health. Sydney: NSW Department of Health.

32. Prochaska JO, DiClemente CC \& Norcross JC (1992) In search of how people change: applications to the addictive behaviors. Am Psychol 47, 1102-1114.
33. Pollard C, Lewis J \& Miller M (2001) Start Right-Eat Right award scheme: implementing food and nutrition policy in child care centres. Health Educ Behav 28, 320-330.

34. Matwijczyk L, Colmer K \& McWhinnie J (2007) An evaluation of a nutrition intervention at childcare centres in South Australia. Health Promot J Aust 18, 159-162.

35. Erinosho T, Dixon LB, Young C et al. (2011) Nutrition practices and children's dietary intakes at 40 child-care centers in New York City. J Am Diet Assoc 111, 1391-1397.

36. Whitaker RC, Gooze RA, Hughes CC et al. (2009) A national survey of obesity prevention practices in Head Start. Arch Pediatr Adolesc Med 163, 1144-1150.

37. NSW Department of Health (2013) Fresh Tastes @ School NSW Healthy School Canteen Strategy: Canteen Menu Planning Guide. http://www.healthykids.nsw.gov.au (accessed December 2013).

38. Skouteris H, McCabe M, Swinburn B et al. (2010) Healthy eating and obesity prevention for preschooler: a randomised control trial. BMC Public Health 10, 220. 